TITLE:

\title{
Spawning Periodicity of Sea Urchins at Seto -IV. Hemicentrotus pulcherrimus-
}

AUTHOR(S):

Kobayashi, Naomasa

CITATION:

Kobayashi, Naomasa. Spawning Periodicity of Sea Urchins at Seto -IV. Hemicentrotus pulcherrimus-. PUBLICATIONS OF THE SETO MARINE BIOLOGICAL LABORATORY 1992, 35(6): 335-345

ISSUE DATE:

1992-11-30

URL:

http://hdl.handle.net/2433/176213

RIGHT: 


\title{
Spawning Periodicity of Sea Urchins at Seto \\ IV. Hemicentrotus pulcherrimus ${ }^{1)}$
}

\author{
NaOmasa Kobayashi \\ Biological Laboratory, Doshisha University, Kamikyo-ku, Kyoto, 602, Japan
}

With Text-figures $1-7$ and Tables 1-2

Lunar reproductive rhythms in sea urchins have been reviewed by Kobayashi (1967), Pearse (1975) and Pearse \& Cameron (1991). Most species with such rhythms are tropical diadematid sea urchins. On the other hand, semi-lunar reproductive rhythms have been reported for Lytechinus variegatus in Florida (Moore et al., 1963) and for several species of sea urchins near the Seto Marine Biological Laboratory, in Shirahama on the Kii Peninsula, Japan (Kobayashi, 1967, 1969; Kobayashi \& Nakamura, 1967).

The sea urchin Hemicentrotus pulcherrimus (A. Agassiz) is found abundantly in shallow water under rocks around Seto and other Japanese localities. Although most other Japanese sea urchins spawn from the spring to summer, H. pulcherrimus spawns in the winter months, January through March (Mori et al., 1980). Moreover the seasonal timing of reproduction has been shown to be influenced by seasonal temperature changes (Yamamoto et al., 1988).

To resolve the problems that the spawning of $H$. pulcherrimus is related whether to lunar or to semi-lunar cycle and that the cycle is shown either in the winter spawning season or during all seasons with respect to gonad size, changes in the gonad volume were examined through one to several days or more around the new moon and full moon for three successive years from 1967 to 1969 .

\section{Materials and Methods}

The specimens used for examination were restricted to the sea urchins with a diameter 3.0 to 4.0 $\mathrm{cm}$ which are properly grown for the present reproductive study. About 10 specimens in each sampling day were collected shortly before the water was lowest when their habitat was out from sea water or became shallower. Daily observations around the time of both new and full moon were continued for three periods between July and August in 1967, throughout the year in 1958, and three periods between January and March in 1969. Sampling was mainly carried out around the time of the full and new moon because many sea urchins are known to spawn at that time (around the spring tide) (Kobayashi, 1969).

After collection, the total body weight before dissection and the gonad weight were measured for each individual. The maturation grade of the gonad was divided into five classes, according to the GT ratio; i.e. the ratio of the gonad weight to the total animal (Table 1). After measuring the total animal and gonad weight, fresh smear preparations of squashed gonad fragments were examined under

Publ. Seto Mar. Biol. Lab., 35(6), 335-345, 1992. (Article 13) 
Table 1. Classification of maturation grades in the reproductive period.

\begin{tabular}{|c|c|c|c|}
\hline $\begin{array}{l}\text { Grade of } \\
\text { ripening }\end{array}$ & GT ratio & Gamete in smear & State of gonad \\
\hline I & $<5 \%$ & empty & wholly spent \\
\hline II & $5-9.9 \%$ & almost empty & spent \\
\hline III & $10-14.9 \%$ & germ cells in various stages of ripening & ripening \\
\hline IV & $15-19.9 \%$ & germ cells mostly ripen & mature \\
\hline $\mathrm{V}$ & $20<\quad \%$ & full of ripe germ cells & fully mature \\
\hline
\end{tabular}

microscope.

\section{Results}

In the reproductive period, from January to March, the gonadal contents appeared in the smear were corresponded with their maturation grades (Table 1), and they were quite similar to those in Mespilia globulus (Kobayashi, 1967), Diadema setosum (Kobayashi \& Nakamura, 1967), Tripneustes gratilla, Echinometra mathaei, Anthocidaris crassispina and Echinostrephus aciculatus (Kobayashi, 1969) and E. aciculatus (Kobayashi \& Tokioka, 1976), as in most other sea urchin (Pearse and Cameron, 1992).

In the non-reproducitve season (from April to December), the gonadal contents in respective neuter gonads consisted of many large nutritive phagocytes (Table 2). After late fall, however, some spermatogenic cells or small oocytes appeared.

I. Seasonal variations for each sampling period in the mean GT ratio (1967-1969)

The mean GT ratios fluctuated seasonally (Fig. 1), increasing in winter and decreasing gradually in spring to autumn. Increases in the GT ratio suggest the beginning of spawning season in early winter. Decreases of it indicate the beginning of non-spawning season in spring. The GT ratio was smallest in October and then increased.

Table 2. Glassification of neuter grades in the non-reproductive period.

\begin{tabular}{c|c|c}
\hline \hline $\begin{array}{c}\text { Grade of } \\
\text { neuter }\end{array}$ & GT ratio & Gamete in smear \\
\hline I & $<5 \%$ \\
II & $5-9.9 \%$ \\
III & $10-14.9 \%$ \\
IV & $15-19.9 \%$ \\
V & $20<$ & \\
\hline
\end{tabular}



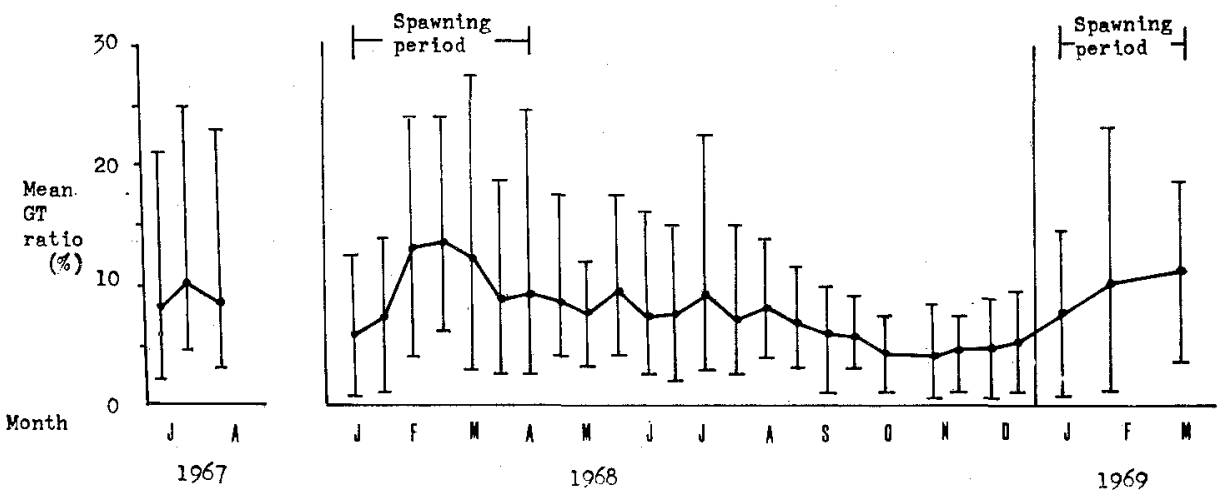

Fig. 1. Seasonal variations for each sampling period in the mean Gonad/Test ratio of Hemicentrotus pulcherrimus at Seto in 1967-1969. Vertical lines indicate range.

II. 1968 (in reproductive season, Fig. 2; Fig. 3)

Successive changes of the mean values of GT ratios for January to April, 1968 are shown in Fig. 2, periods 1-6. The mean values of the GT ratios (5-19\%) were situated mostly on the center of the range of values for each sampling day. The lines connecting the mean values demonstrate a general tendency, with peak values generally occurring the day before and/or after the full and/or new moon.

1. The 1st period (January 14-18, Full moon:15) (beginning in reproductive season)

The peak of the GT ratio was indicated on the 2nd sampling day (8\%), the day of full moon, and the bottom appeared on the 3rd day (5\%). Grades IV and V, however, were not found, and grades I and/or II occurred at above $50 \%$ on all dates (Fig. 3-1), indicating that maturation and spawning had not yet begun.

2. The 2nd period (January 26-February 2, New moon:29)

The peak of the GT ratio was indicated on the 3rd day $(12 \%)$, one day before the new moon. The bottom appeared on the 1 st and 2 nd $(6 \%)$ and the 6 th $(6 \%)$
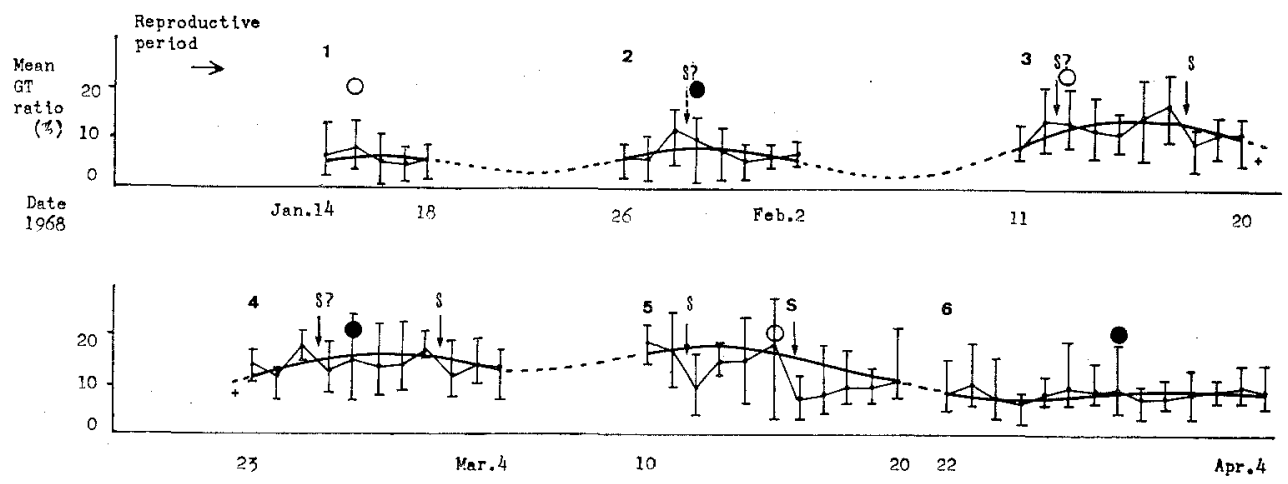

Fig. 2 Successive changes of the GT ratios of Hemicentrotus pulcherrimus in 1968. Vertical lines indiate each the range of individual variations of GT ratio. Arrows indicate suggested times of spawning. 

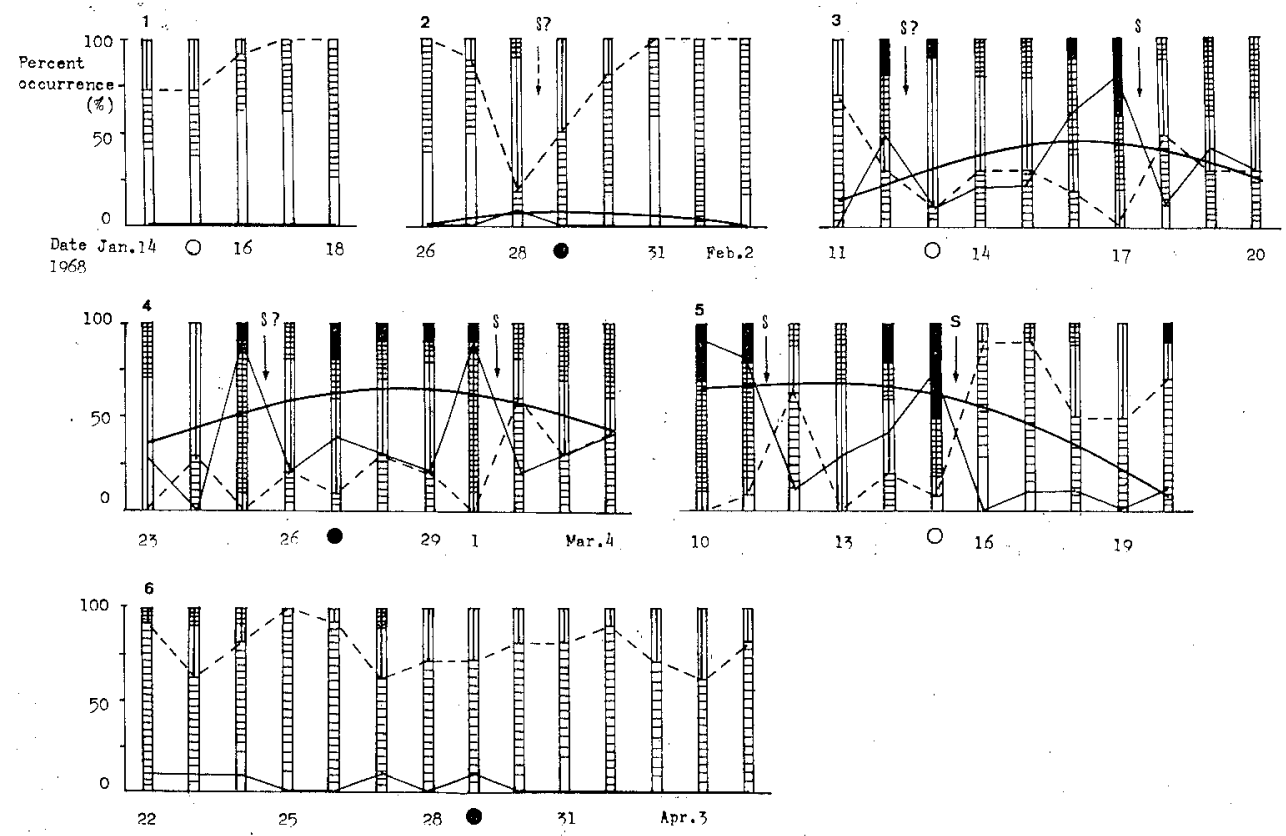

Fig. 3. Percent occurrences of respective maturation grades in 1968 during the spawning season. Smooth curve lines indicate suggested fluctuation of mean GT ratios.

$O$ : full moon, : new moon - : successive changes of grades IV and $\mathrm{V}$

- - : successive changes of grades I and II

$\square:$ I $\square$ : II $\square$ : III $\square$ : IV $\square: V$

day. The appearance of grade IV was found only on the 3rd day (Fig. 3-2), one day before the new moon. Grades I and/or II predominated on the 1st, 2nd and 5 th to last days as the dotted line in higher percentages.

3. The 3rd period (February 11-20, Full moon:13)

The peak of the GT ratio was shown on the 8 th $(14 \%)$ and 7 th days $(18 \%)$, one day before and 4 days after the full moon respectively. The bottom appeared on the 1 st $(9 \%), 5$ th $(11 \%)$ and 8 th $(10 \%)$ days.

The appearance of grades IV and/or $V$ was found on the 2 nd to the last days, one day before to seven days after the full moon. Grade II predominated only on the 1st days as shown by the dotted line in higher percentage, while the peak of the grades IV and V was shown very clearly on the 2nd and 7th days by the solid line (Fig. 3-3).

4. The 4th period (February 23-March 4, New moon:5)

The peak of the GT ratio was shown on the 3rd (19\%) and 8th (17\%) days, 2 days before and 3 days after the new moon respectively. The bottom appeared on the 2nd $(12 \%), 4$ th $(13 \%)$ and 9 th $(12 \%)$ days.

Grade IV and/or V was found on the lst and the 3rd to last days, five days before to after the new moon (Fig. 3-4). Grade II peaked on the 9th day as shown by the dotted line, while the peak of the grades IV and $\mathrm{V}$ was shown very clearly 
on the 3rd and 8 th days as shown by the solid line. There was a reverse correlation between solid and dotted lines.

5. The 5th period (March 10-20, Full moon:15)

The peak of the GT ratio was shown on the 1 st (19\%) and 6th (19\%) days, 5 days before and the day of full moon. The bottom was appeared on the 3 rd $(9 \%)$ and 7 th $(7 \%)$ days.

The appearance of grades IV and/or V was found on nearly the same days, as well as on the 7 th and 10th days, one and four days after full moon respectively (Fig. 3-5). Grades I and/or II was shown on the 3rd, 7th, 8th and 11th days, while, the peak of the grade IV and V was shown very clearly on the 1st and 6th days, as the solid line. There was the reverse correlation between solid and dotted lines.

6. The 6th period (March 22-Apeil 4, New moon:29) (end of breeding season)

The peak of the GT ratio was shown on the 2nd $(10 \%), 6$ th $(10 \%)$ and 13 th $(10 \%)$ days, 6 and 2 days before and 5 days after the new moon respectively. The bottom appeared on the 4 th $(7 \%)$ and 9 th $(7 \%)$ days. Grades IV was found on the 1st to 3rd, 6th and 8th days, seven to five and two days before the new moon, and the day of new moon respectively (Fig. 3-6). Grades I and/orII predominated on all days as the dotted line. There were a few grade IV (but no grade V), on the 1 st to 3 rd, 6th and 8 th days. Spawning was probably finished by the time of these samples.

In summary, these data indicate that spawning occurred 6 times, around new and full moon throughout the reproductive season of 1968. And the days are at most 4 days distant from the nearest new and full moon.

III. 1969 (in reproductive season)

Successive changes of the mean values of $\mathrm{GT}$ ratios and reproductive grades are shown in Fig. 4-1-3. The mean values of the GT ratio $(5-14 \%)$ were situated
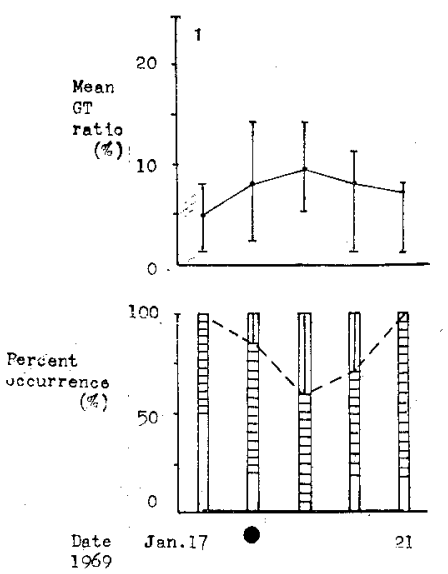

2
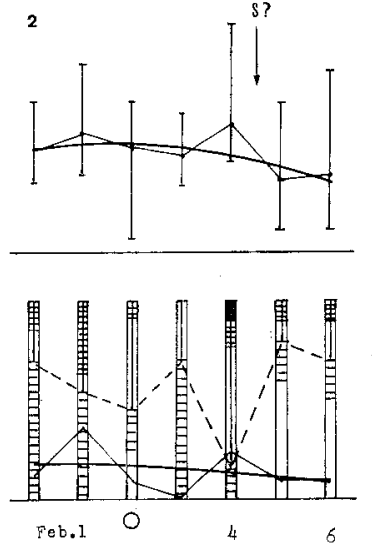
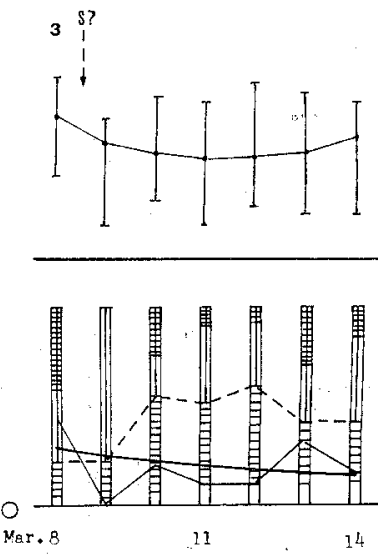

Fig. 4. Successive changes in the gonads of Hemicentrotus pulcherrimus in winter 1969. Upper: Gonad/Test (GT) ratios: vertical lines indicate range of individual values Lower: Maturation grade. For signs see Fig. 3. 
mostly on the center of the range in variation for each sampling day. The lines connecting with the mean values demonstrate a general tendency.

For the first period (January 17-21, new moon:18) (beginning of reproductive season), the peak of the GT ratio was indicated on the 3rd day (10\%), the day of new moon, and the bottom appeared on the 1 st $(5 \%)$ and 5 th $(7 \%)$ day. Grades IV and/ or $\mathrm{V}$ were not found at all, while grades I and/or II predominated on all days as the dotted line (Fig. 4-1). Spawning had not yet begun at this time.

For the period (January 31-February 6, Full moon:2), the peak of the GT ratio was indicated on the 2 nd $(12 \%)$ and 5 th $(13 \%)$ days, one day before and two day after the full moon, and the bottom appeared on the 6th $(7 \%)$ and 7 th $(7 \%)$ day. Grades IV and/or V were found on the 1 st to 3 rd and 5 th to 7 th dyas as shown by the solid line(Fig. 4-2). Grades I and/or II was shown on 1st to 4th, 6 th and 7 th days as the dotted line. There was a considerable reverse ocrrelation between solid and dotted lines. Spawning probably cocurred mainly between the 5 th and 6th days, 2 days after the full moon.

For the 3rd period (March 8-14, Full moon:4), the peak of the GT ratio was indicated on the 1 st $(14 \%)$ ant last $(12 \%)$ days, 4 and 10 days after the full moon, and bottom appeared on the 4th $(10 \%)$ day. The appearance of grade IV were found on the 1st and 3rd to last days as shown by the solid line, but no grade $\mathrm{V}$ animals were found (Fig. 4-3). Grades I and/or II was shown on 3rd and 5th day as the dotted line. Swawning probably occurred mainly the lst day, 1 day after the full moon.

\section{1967 (in non-reproductive season)}

Successive changes of the mean values of GT ratios and neuter gonad grades are shown in Fig. 5-1-3. The mean GT values (3-15\%) were situated mostly on the center of the range of values for each sampling day. The lines connecting the mean values demonstrate a general tendency, with peak value occurring the day be-

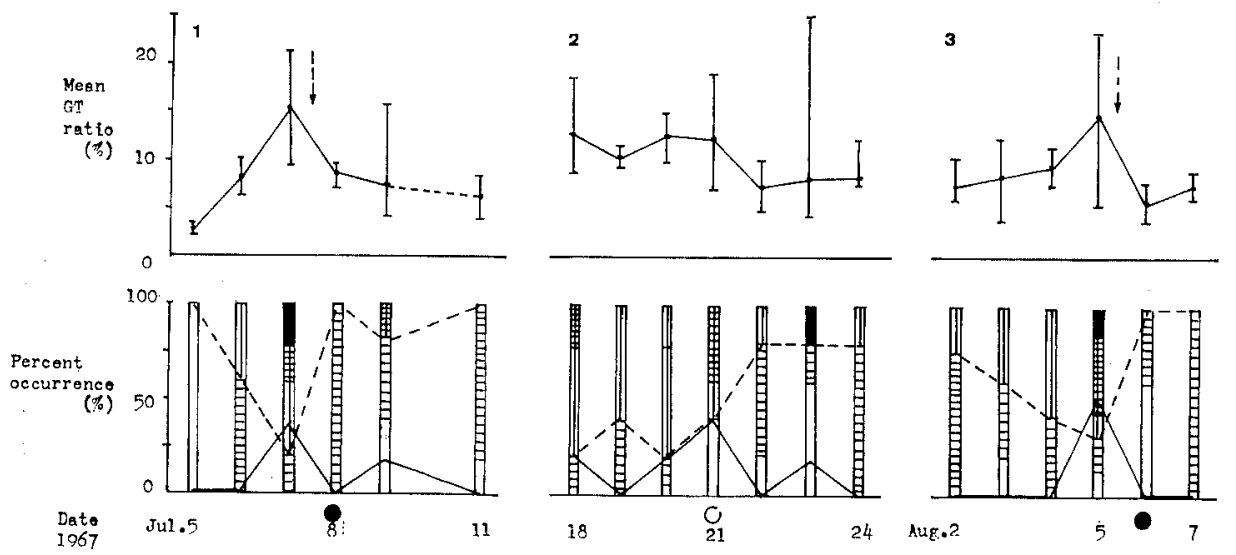

Fig. 5. Successive changes in the gonads of Hemicentrotus pulcherrimus in summer 1967. Upper: Gonad/Test (GT) ratios; vertical lines indicate range of individual values. Lower: Neuter grade. For signs see Fig. 3. 
fore the new moon of both July and August. Similarly, the occurrences of individuals in respective GT values shows a general tendency of higher grade being more numerous before the new moon, and on the full moon.

For the 1st period (July 5-11, New moon:8), the bottom of the ratio appeared on the 1 st $(3 \%)$ and last $(6 \%)$ days, while the peak was indicated clearly on the 3rd day (15\%), one day before the new moon. More than $50 \%$ of the sample was at grades I and/or II on the 1st, 2nd, 4th, 5th and 7th days, while grades IV and/or $\mathrm{V}$ individuals were found on the 3rd day, one day before new moon, and a grade IV individual was found on day 5, one day after the new moon. There were reverse correlation between the occurrence of grades I and II and grades IV and V (Fig. 5-1).

For the 2nd period (July 18-24, Full moon: 21), the mean of the GT was highest on 1 st 4 days $(10-13 \%)$, up to the day of the full moon, then was low for the following 3 days, but there was considerable variation, especially on the 6 th day. The appearances of grades IV and/or V individuals were found on the 1st, 3rd, 4th and 6th days. Grades I and/or II predominated on the 5th to 7th days (Fig. 5-2).

For the 3rd period (August 2-7, New moon:6), the bottom of the GT ratio appeared on the 1 st $(7 \%)$ and 5 th day $(5 \%)$, while the peak was indicated clearly on the 4 th day $(15 \%)$, one day before new moon. Grades I and/or II were above $50 \%$ on the 1st, 2nd, 5th and 6th days. Grades IV and V were present only on the 4th day, one day before new moon. The pattern of changes seen around the August new moon was very similar to that seen around the July new moon (Fig. 5-3).

V. 1968 (in non-reproductive season)

Successive changes of the mean values of GT ratios for April to August, 1968 are shown in Fig. 6, periods 1-9. The mean values of the GT ratios (6-14\%) were

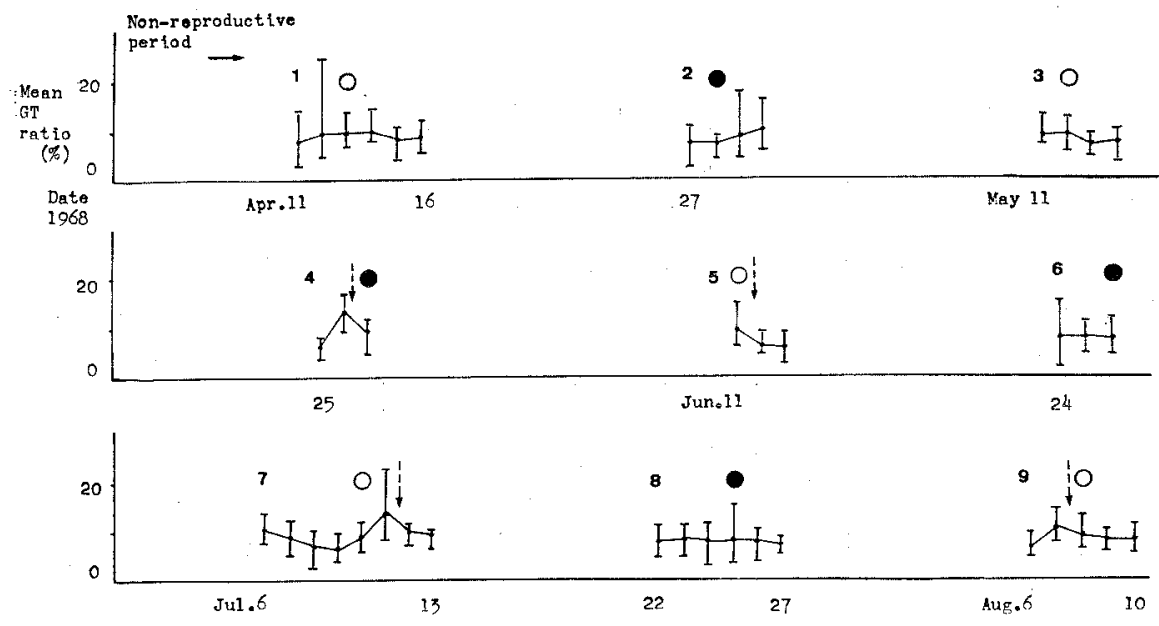

Fig. 6. Successive changes of the GT ratios of Hemicentrotus plucherrimus in 1968. Vertical lines indicate each the range of individual variations of GT ratio. 
situated mostly on the center of the range of values for each sampling day. The lines connecting the mean values demonstrate a general tendency, with peak values generally occurring the day before and/or:after the new and/or full moon.

1. The 1st period (April 11-16, Full moon:13)

The peak of the GT ratio was shown on the 2 nd day $(10 \%)$ one day before the full moon. The bottom was shown on the 5th day (8\%) (Fig. 6-1).

The occurrences of individuals in respective grades in percent were illustrated in Fig. 7 - Grades IV and V were found only on 2nd day, one day before full moon. Grades I and/or II predominated on all days as shown by the dotted line.

2. The 2nd period (April 27-30, New moon:28)

The peak of the GT ratio was indicated on the last day $(11 \%)$, two days after the new moon. The bottom was shown on the 2nd day (8\%) (Fig. 6-2). Grade IV was found on last 2 days, one and two days after the new moon, while grades I and/or II predominated on all days except the last day (Fig. 7-2).

3. The 3rd period (May 11-14, Full moon:12)

The peak of the GT ratio was shown on the 2 nd day $(9 \%)$, the day of full moon. The bottom was indicated on the 3rd day (6\%). (Fig. 6-3). Grdaes IV and $\mathrm{V}$ were not found, but grades I and/or II predominated on all days (Fig. 7-3).

4. The 4th to 6th periods (May 25-27, New moon:27; June 11-13, Full moon:11; June 24-26, New moon:26)

There were observed only three days respectively for each of these periods. The peak of the GT ratio were shown on the 2 nd day (13\%) - one day before new moon on 4 th period, on the first day $(10 \%)$ or before - the day of full moon - on 5th period and not at all on 6 th period $(8 \%)$. On 4 th and 5 th periods, the bottoms could not be detected because of the short term data $(<6 \%$ ) (Figs. 6, 4-6). Grades IV was found on 2 nd day, one day before new moon, on 4th period and on 1st day, the day of full moon, on 5 th period as the solid line. Grades I and/or II predominated on most days except on 2 nd and 3 rd day of 4 th period, as shown by the dotted line. On 4th peri-
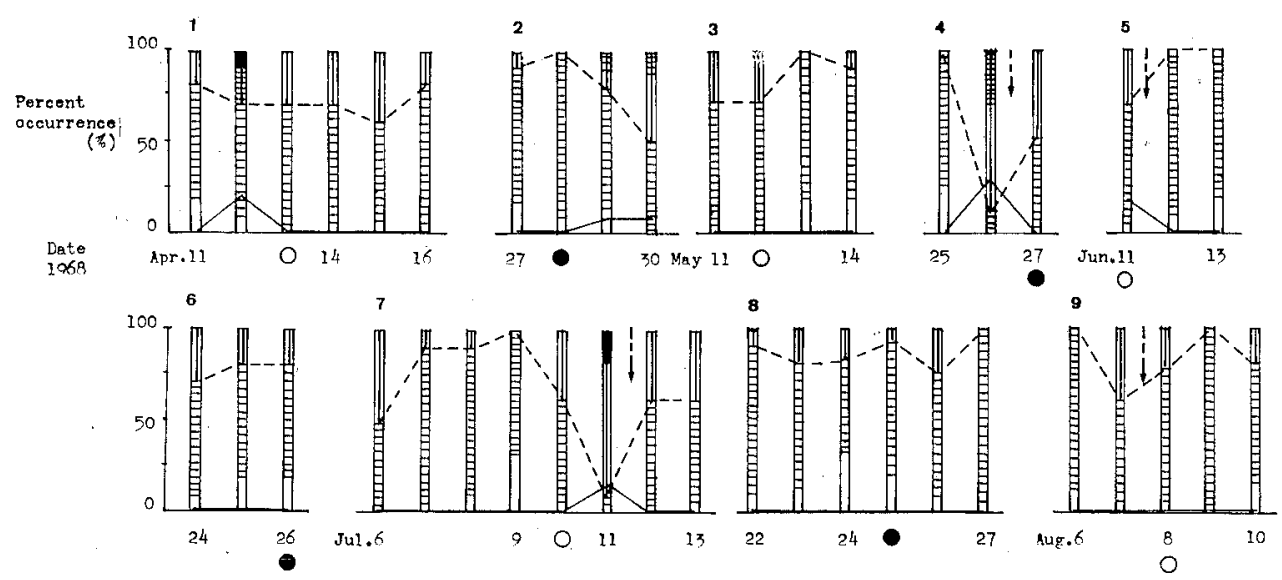

Fig. 7. Percent occurrences of respective neuter grades in 1968 during the non-breeding season. For signs see Fig. 3. 
od, there were the reverse correlation between solid and dotted lines (Figs. 7,4-6).

5. The 7th period (July 6-13, Full moon: 10)

The peak of the GT ratio was shown on the 6 th day (14\%), one day after of full moon. The bottom was shown on the 4 th day $(6 \%)$ (Fig. 6-7). Grade $V$ was found only on 6th day, one day after full moon as the solid line, while grades I and/ or II predominated on the 2 nd to 5 th and last days (Fig. 7-7)

6. The 8th period (July 22-27, New moon:25)

There was no pattern in either GT ratio or grades during this sampling period (Fig. 6-8). Grades I and/or II predominated on all days, and grades IV and $\mathrm{V}$ were not found (Figs. 7-8).

7. The 9th period (August 6-10, Full moon:8)

The peak of the GT ratio was shown on the 2 nd day (10\%), one day before full moon. The bottom was 1st day (7\%) (Fig. 6-9). Grades I and/or II predominated on all days, and grades IV and $V$ were not found (Fig. 7-9).

8. The 10th to 17 th periods (August 23-25 to December 21 and 22)

The appearance of grade IV or $\mathrm{V}$ was not found in any of these sampling periods and grades I and/or II predominated. The gonads were always small and undeveloped (Fig. 1).

\section{Discussion and Conclusion}

In many kinds of sea urchins, it has been reported that reproduction is repeated in certain rhythm correlated with the lunar cycle. In these species mature individuals in both sexes discharge genital products and spent in a period round the full or new moon during the breeding season (literatures referred in review by Kobayashi, 1967, Pearse, 1975 and Pearse \& Cameron, 1991). Lunar rhythms are particularly prominent in diadematoids; populations of some species or populations were found to be full of gametes near the time of the full moon, while the others were observed to be full of gametes near the time of the new moon. On the other hand, some populations of the urchins do not appear to have lunar spawning rhythms: Moreover, populations of one species, Diadema setosum, was found to show gametogenic asynchrony with respect to the moon light cycle, indicating that factors other than moonlight, i.e. sea temperature, might be important in regulating and synchronizing the timing of gametogenesis in this species (Pearse, 1968).

In addition, Moore et al. (1963) reported that Lytechinus variegatus in Florida spawned at the time of both the new moon and the full moon - that is, with a semilunar periodicity of spawning. Similar semi-lunar spawning rhythms have been reported at Seto for Mespilia globulus by Kobayashi (1967), Diadema setosum by Kobayashi \& Nakamura (1967) and for Tripneustes gratilla, Echinometra mathaei, Anthocidaris crassispina and Echinostrephus aciculatus by Kobayashi (1969). The results obtained in the present observations with Hemicentrotus pulcherrimus seem consistent with the view of a semi-lunar rhythms. The percent of spent individuals attained a minimum in a few days around the full and new moon fluctuations in the occurrence 
of mature and fully mature individuals were found to be generally the inverse of spent ones. It is possible that the smooth curve line can draw as for the fluctuation of mean GT ratios (the lines drawn in Figs 2-4). The peak of each curve appeared in the few days around the full and new moon in the reproductive season. These data are enough to admit the enhancement of reproductive activity in the period of both the full and new moon in breeding season as has been reported in other sea urchins at Seto.

High fluctuations in the occurrence of individuals in respective maturation grade during the period of mid-breeding season (February to mid-March) seem to suggest that the gonad will be again full of ripe genital products in a few days after the spawning. This can be explained as follows: the bulk of germ cells do not mature at a time of the spawning, but some part of the cells remain immature and become ripe then to be discharged within a few ensuing days. Low fluctuations in the occurrence of individuals in respective maturation grade during the period of early and late-breeding season (January and late-March) were observed. On the other hand, high fluctuations in the occurrence of individuals in respective grade during some period of non-breeding season (late-May to early August) were found. Perhaps there may be a physiological rhythm of gonad that conforms to the semi-lunar cycle.

Regarding the seasonal changes in the gonad index, the slow and fluctuated decline occurs from April, after spawning, to October-November, before gametogenesis is renewed. In most sea urchins, this "inactive" phase is when the nutritive cells are being restored and the gonad grows to become filled with nutritive phagocytes, for example Echinometra mathaei (Pearse, 1969) suggested that the gonad need to accumulate some minimum amount of nutrients before gametogenesis would begin. However, such nutritive accumulation for gametogenesis does not appear on Hemicentrotus plucherrimus in summer. Perhaps body growth proceeds mainly in the summer, at the expense of the gonads; a number of papers suggest this (Pearse \& Cameron's review, 1991). This process can explain the decline of the gonad index in the inactive season.

Semi-monthly spring-neap tidal cycle is regularly repeated at Seto (see Figs in Kobayashi, 1969 and Yanagisawa \& Tanase, 1973). And it may influence to reproductive periodicity of sea urchins living at the coast. The semi-lunar periodicity of gonad maturation confirmed on many sea urchins at Seto (Mespilia globulus (Kobayashi, 1967), Diadema setosum (Kobayashi \& Nakamura, 1967), Tripnetstes gratilla, Echinometra mathaei, Anthocidaris crassispina and Echinostrephus aciculatus (Kobayashi, 1969). And Pseudocentrotus depressus seems to allude to a semi-lunar periodicity at Seto (unpublished data). But Yanagisawa and Tanase's work (1973) in Temnopleurus reevesi seem to be only lunar periodicity near the time of the new moon, known as a rare case.

As Seto, Shirahama in Wakayama Prefecture, is situated near the southern distributional limit of Hemicentrolus pulcherrimus, the higher water temperature might be critical for the species. Seto is also situated near the northern limit of distribu- 
tion of many tropial subtropical species of sea urchins; for these species the lower water temperature must be critical. In such circumstances, the spawning activity of these urchins might be under the control of the lunar temperature cycles as proposed by Moore et al. (1963). He reported that the spawning occur throughout the summer at Miami, but it was briefer in Bermuda where it exhibited a lunar rhythm under the lower sea temperature. Sea temperature, but not photoperiod, is important for controlling the reproduction of $H$. pulcherrimus - is suggested by Yamamoto et al. (1988), and confirmed by Ito et al. (1989).

The author wishes to express his thanks to the Director and Staff of the Seto Marine Biological Laboratory who gave him every facility for his researches at the Laboratory. His thanks are also due to Professor Emeritus Takashi Tokioka of the Laboratory for his advices and valuable criticisms. His gratitudes are also due to Professor John S. Pearse of the University of California, Santa Cruz for his kind reading and criticism of this manuscript.

\section{References}

Ito, S., M. Shibayama, A. Kobayakawa \& Y. Tani. 1989. Promotion of maturation and spawning of sea urchin Hemicentrolus pulcherrimus by regulating water temperature. Nippon Suisan Gakkaishi, 55: 757-763.

Kobayashi, N. 1967. Spawning periodicity of sea urchins at Seto I. Mespilia globulus. Publ. Seto Mar. Biol. Lab., 14: 403-414.

- 1969. Spawning periodicity of sea urchins at Seto III. Tripenustes gratilla, Echinometra mathaei, Anthocidaris crassispina and Echinostrephus aciculatus. Sci. Fngin. Rev. Doshisha Univ., 9: 245269 (in Japanese with English resume).

\& K. Nakamura. 1967. Spawning periodicity of sea urchins at Seto II. Diadema setosum. Publ. Seto Mar. Biol. Lab., 15: 173-184.

\& T. Tokioka. 1976. Preliminary observation on the maturation of the burrowing sea urchins, Echinostrephus aciculatus (A. Agassiz), in the vicinity of Seto. Publ. Seto Mar. Biol. Lab., 23: 57-62.

Moore, H.B., Thelma Jutare, J.C. Bauer \& J.A. Jones. 1963. The biology of Lytechnius variegattus. Bull. Mar. Sci., 13: 23-53.

Mori, T., T. Tsuchiya \& S. Amemiya. 1980. Annual gonadal variation in sea urchins of the orders echinothurioda and echnioida. Biol. Bull., 159: 728-736.

Pearse, J.S. 1968. Patterns of reproductive periodicities in four species of Indo-Pacific echinoderms. Proc. Indian Acad. Sci., 67: 247-279.

1969. Reproductive periodicities of Indo-Pacific invertebrates in the Gulf of Suez. II. Echinoid Echinometra mathaei (De Blainville). Bull. Mar. Sci., 19: 580-613.

- 1975. Lunar reproductive rhythms in sea urchins. A review. J. Intrediscipl. Cycle Res., 6: 47-52.

— \& R.A. Cameron. 1991. Echinodermata: Echinoidea, in A.C. Giese, J.S. Pearse \& V.B. Pearse eds., Reproduction of marine invertebrates. Vol. 6. 513-662. Blackwell Sci./Boxwood Press.

Yamamoto, M., M. Ishine \& M. Yoshida. 1988. Gonadal maturation independent of photic conditions in laboratory-reared sea urchins. Pseudocentrotus depressus and Hemicentrotus pulcherrimus. Zool. Sci., 5: 979-988.

Yanagisawa, Y. \& H. Tanase. 1973. An outbreak of the sea urchin, Temnopleurus (Treumatica) reevesi (Gray), in the vicinity of Shirahama. Nankiseibutsu, 15:37-40 (in Japanese). 